\title{
COMPONENTES DA PRODUÇÃO E PRODUTIVIDADE DE CULTIVARES DE ARROZ E FEIJÃO EM FUNÇÃO DE CALCÁRIO E GESSO APLICADOS NA SUPERFÍCIE DO SOLO (1)
}

\author{
ROGÉRIO PERES SORATTO $\left(2^{*}, 4\right)$, CARLOS ALEXANDRE COSTA CRUSCIOL $(2,4)$, \\ FRANCISCO FUJITA DE CASTRO MELLO $\left({ }^{3}\right)$
}

\begin{abstract}
RESUMO
A utilização do gesso agrícola e de cultivares mais tolerantes à acidez do solo podem ser alternativa para viabilizar o cultivo em sistema plantio direto sem a incorporação prévia do calcário. Este trabalho foi realizado com o objetivo de avaliar o efeito da aplicação superficial de calcário e gesso agrícola nos componentes da produção e na produtividade de grãos de cultivares de arroz e feijão. O experimento foi instalado em Latossolo Vermelho distroférrico, anteriormente manejado no sistema convencional de preparo do solo, em Botucatu (SP). O delineamento foi em blocos casualizados com parcelas sub-subdivididas e quatro repetições. Nas parcelas, os tratamentos foram os seguintes: quatro doses de calcário dolomítico (0,1.100, 2.700 e $\left.4.300 \mathrm{~kg} \mathrm{ha}^{-1}\right)$; nas subparcelas, aplicação ou não de $2.100 \mathrm{~kg} \mathrm{ha}^{-1}$ de gesso agrícola; e nas sub-subparcelas, foram cultivadas duas cultivares de arroz de terras altas (Caiapó e IAC 202), no ano agrícola 2002/2003, e duas de feijão (Pérola e Carioca), em 2003/2004. O número de panículas por m², o número de espiguetas por panícula, a massa de mil grãos e a produtividade de grãos das cultivares de arroz aumentaram pela aplicação de calcário. A aplicação de gesso aumentou o número de panículas por $\mathrm{m}^{2}$ e a produtividade de grãos da cultivar Caiapó, mas reduziu o número de panículas e não afetou a produtividade da cultivar IAC 202. A calagem, na ausência de gesso, aumentou o número de vagens por planta e a produtividade de grãos das cultivares de feijão. A aplicação de gesso reduziu o número de vagens por planta da cultivar Carioca de feijão, mas não alterou outros componentes da produção e a produtividade de grãos. A dose de calcário para elevar a saturação por bases a 70\% foi a mais adequada para ambas as culturas. O uso de cultivares mais tolerantes à acidez do solo proporciona maior produtividade no início do sistema plantio direto, quando ainda não houve efetiva correção do solo pela aplicação de corretivos em superfície.
\end{abstract}

Palavras-chave: Oryza sativa, Phaseolus vulgaris, acidez do solo, calcário.

\section{ABSTRACT \\ YIELD COMPONENTS OF RICE AND BEAN CULTIVARS AS AFFECTED BY LIME AND PHOSPHOGYPSUM APPLIED IN SOIL SURFACE}

The use of phosphogypsum and more tolerant cultivars to soil acidity can be an alternative to enable crops in no-tillage system, without previous lime incorporation. This trial was carried out to evatuate the effects of lime and phosphogypsum surface application on yield components as well as on grain yield of upland rice and common bean cultivars, in no-tillage system. The experiment was done on a Haplorthox, previously cultivated on conventional tillage system, in Botucatu, São Paulo State, Brazil. A randomized complete block design, in split-split-plot scheme, and four replications were used. The plots comprised four dolomite limestone rates $\left(0,1,100,2,700\right.$, and 4,300 $\left.\mathrm{kg} \mathrm{ha}^{-1}\right)$; in the subplots phosphogypsum was applied at the rates: 0 and 2,100 $\mathrm{kg} \mathrm{ha}^{-1}$. Two upland rice cultivars ('Caiapó' and 'IAC 202') were grown in the sub-subplots in 2002/ 2003 cropping season, and two common bean cultivars ('Carioca' and 'Pérola'), in 2003/2004. The number of panicles per $\mathrm{m}^{2}$, spikelets per panicles, mass of 1,000 grains, and grain yield of upland rice cultivars was increased with lime surface application. Phosphogypsum application increased the number of panicles per $\mathrm{m}^{2}$ and grains yield of the 'Caiapó' rice cultivar, but decreased the number of panicles per $\mathrm{m}^{2}$ and did not affect grain yield of the 'IAC 202' cultivar. Lime surface application, without phosphogypsum, increased the number of pods per plant and grain yield of both bean cultivars. Phosphogypsum application decreased the number of pods per plant of the 'Carioca' bean cultivar, but did not affect other yield components or grain yield. The lime dose to raise the base saturation to $70 \%$ was optimal for both crops. Using soil acidity tolerant cultivars promoted higher crop yields in no-till systems establishment, even when the effective soil amelioration had not yet been achieved.

Key words: Oryza sativa, Phaseolus vulgaris, soil acidity, liming.

(1) Recebido para publicação em 22 de março de 2010 e aceito em 11 de junho de 2010.

$\left(^{2}\right)$ Departamento de Produção Vegetal, Faculdade de Ciências Agronômicas (FCA), Universidade Estadual Paulista (UNESP), Caixa Postal 237, 18603-970 Botucatu (SP). E-mail: soratto@fca.unesp.br $\left(^{*}\right)$ Autor correspondente; crusciol@fca.unesp.br

(3) Universidade de São Paulo (USP), Centro de Energia Nuclear na Agricultura (CENA), Av. Centenário, 303, São Dimas, $13400-970$ Piracicaba (SP). E-mail: ffcmello@esalq.usp.br

(4) Com bolsa de produtividade em pesquisa do $\mathrm{CNPq}$. 


\section{INTRODUÇÃO}

O sistema plantio direto (SPD), associado à rotação de culturas, é uma das melhores alternativas para a manutenção da sustentabilidade dos recursos naturais na utilização agrícola dos solos, porque auxilia no controle da erosão, propicia maior disponibilidade de água e nutrientes às plantas e melhora atributos físicos e químicos do solo devido ao aumento do teor de matéria orgânica (BALBINO et al., 1996; CAIRES et al., 2005). Por esses motivos, e também pela economia de combustíveis com as operações de preparo do solo e incorporação de corretivos, tem crescido o interesse no estabelecimento de culturas no SPD, em áreas anteriormente cultivadas no sistema convencional de preparo do solo ou sob pastagens, sem promover o revolvimento do solo para incorporação de corretivos (CAIRES et al., 2003).

Como o calcário é produto de baixa solubilidade, sua incorporação geralmente aumenta a eficiência da calagem. Contudo, esse procedimento contraria o princípio de movimentação mínima da camada superficial do solo preconizado no SPD (PIREs et al., 2003). Por outro lado, como a reação do calcário é geralmente limitada à camada de incorporação (PAVAn e Oliveira, 2000), sem esta operação tem-se menor contato entre as partículas do corretivo e os colóides do solo, fazendo com que a calagem em superfície tenha efeito mais lento na diminuição da acidez do subsolo, que depende da lixiviação de sais através do perfil (Toma et al., 1999; CAIRES et al., 2003; CAIRES et al., 2005).

A aplicação superficial de gesso agrícola, um subproduto da indústria do ácido fosfórico, que contém principalmente o sulfato de cálcio, é uma alternativa para a melhoria do ambiente radicular nas camadas subsuperficiais (SousA et al., 1996; TomA et al., 1999). O gesso pode ser utilizado em solos ácidos como insumo complementar ao calcário, devido à ação limitada da calagem às camadas superficiais, principalmente nos primeiros anos de cultivo (SumNer et al., 1986; CAIRES et al., 2003; CAIRES et al., 2004). O interesse pelo uso de gesso agrícola para diminuir o problema da acidez do subsolo em SPD é decorrente da sua maior solubilidade. O gesso agrícola aplicado na superfície do solo movimenta-se ao longo do perfil sob a influência da percolação de água (QuAGGIO et al., 1993; CAIRES et al., 2004). Como consequência, obtém-se aumento no suprimento de cálcio e redução da toxidez de alumínio no subsolo (Adams e Lund, 1966; Toma et al., 1999; CAIRES et al., 2003). Porém, apesar do grande potencial de uso do gesso agrícola, ainda existem dúvidas quanto ao método de recomendação do produto e em que condições são esperadas respostas das culturas à aplicação superficial de gesso em combinação com calcário na implantação do SPD, principalmente nas regiões de inverno seco.
Outra estratégia para obter produtividades satisfatórias no período de implantação do SPD, com aplicação superficial de corretivos, é o cultivo de espécies tolerantes à acidez do solo. O arroz de terras altas pode ser uma opção interessante, por ser considerado adaptado a essas condições (FAGERIA, 2000), entretanto dentro da espécie existem cultivares que diferem em sua resposta ao estresse de $\mathrm{Al}$ e à calagem (FAGERIA, 1982; FERREIRA et al., 1986; DuARTE et al., 1999). Na cultura do feijão, também foram observadas respostas diferenciadas de cultivares à calagem (VALE, 1994; SILVA, 2002), podendo, as mais tolerantes à acidez, serem utilizadas no período em que o calcário aplicado superficialmente ainda não promoveu correção da acidez, principalmente, nas camadas sub-superficiais do solo.

$\mathrm{Na}$ maioria dos trabalhos realizados nota-se apenas o efeito da aplicação de calcário e de gesso na nutrição e produtividade das culturas, sem, no entanto, verificar qual componente da produção foi alterado. Segundo ForNASIERI FILHO e ForNASIERI (1993), a produção da cultura de arroz é determinada por quatro componentes: número de panículas por $\mathrm{m}^{2}$, número de espiguetas por panícula, porcentagem de espiguetas férteis e massa de mil grãos. $\mathrm{Na}$ cultura do feijão, os componentes da produção são: população final de plantas, número de vagens por planta, número de grãos por vagem e massa de cem grãos (PORTES, 1996). Em ambas as culturas, todos os componentes da produção podem ser alterados por condições climáticas, fertilidade do solo e práticas agrícolas, o que refletirá na produtividade de grãos. Dessa forma, é importante conhecer não só o efeito da aplicação de calcário e gesso em superfície na produtividade, mas também quais componentes da produção são mais afetados.

O presente trabalho objetivou avaliar o efeito da aplicação de calcário e gesso em superfície, na implantação do SPD, nos componentes da produção e na produtividade de grãos de cultivares de arroz e feijão.

\section{MATERIAL E MÉTODOS}

O trabalho foi realizado no município de Botucatu, SP ( $48^{\circ} 23^{\prime} \mathrm{W}$ e $22^{\circ} 51^{\prime} \mathrm{S}$; $765 \mathrm{~m}$ de altitude). O clima, conforme a classificação de Köppen, é do tipo Cwa, que se caracteriza como tropical de altitude, com inverno seco e verão quente e chuvoso. Durante os meses de realização do experimento, nos dois anos agrícolas, foram registradas as precipitações pluviais diárias na área experimental (Figura 1).

O solo do local é Latossolo Vermelho distroférrico, o qual estava há dois anos em pousio. Em fevereiro de 2001, foi cultivada soja (safrinha) mediante preparo de solo convencional (uma aração e duas gradagens). 


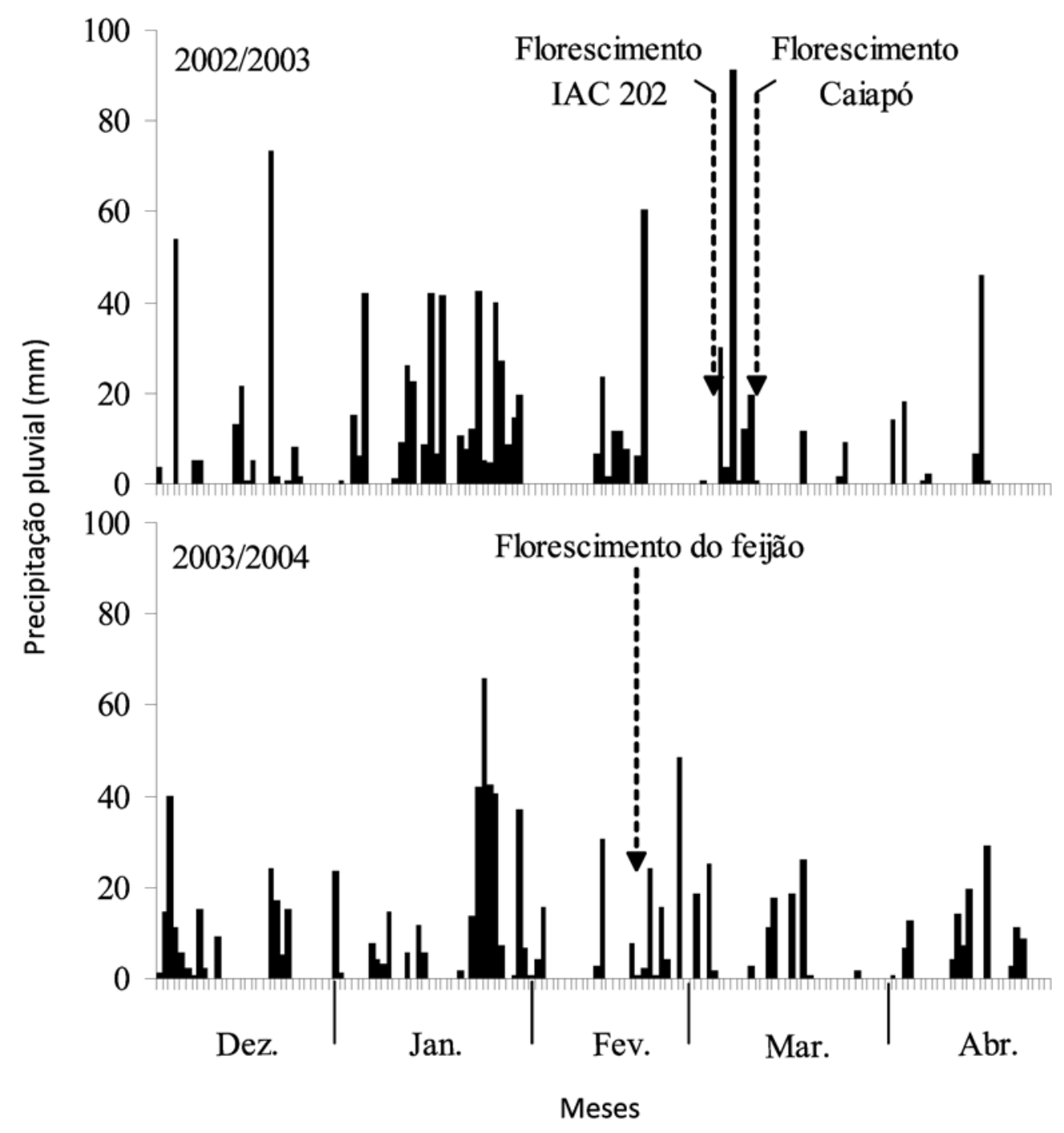

Figura 1. Valores diários de precipitação pluvial $\left(\mathrm{mm} \mathrm{dia}^{-1}\right)$ obtidos na área experimental durante o período de dezembro a abril, nos anos agrícolas de 2002/2003 e 2003/2004 e datas em que as culturas de arroz e feijão atingiram o florescimento pleno. Botucatu (SP).

Em outubro de 2001, a área experimental foi subsolada e cultivada com guandu (Cajanus cajan (L.) Millsp.), o qual foi manejado com triturador de palha em $2 / 10 / 2002$. Em agosto de 2002, foram coletadas amostras de solo nas profundidades de 0-0,20 e 0,200,40 m, para caracterizações química (RAIJ et al., 2001) e granulométrica, obtendo-se na camada arável: matéria orgânica $=21 \mathrm{~g} \mathrm{dm}^{-3}, \mathrm{pH}\left(0,01 \mathrm{~mol} \mathrm{~L}^{-1} \mathrm{CaCl}_{2}\right)=4,2, \mathrm{P}$ $($ resina $)=9 \mathrm{mg} \mathrm{dm}^{-3}, \mathrm{~K}, \mathrm{Ca}, \mathrm{Mg} \mathrm{Al}^{3+}$ e CTC $=1,2,14,5$, 6,5 e $58 \mathrm{mmol}_{\mathrm{c}} \mathrm{dm}^{-3}$, respectivamente, $\mathrm{V}=37 \%$ e teores de areia, silte e argila, respectivamente, de 545, 108 e 347 $\mathrm{g} \mathrm{kg}^{-1} \mathrm{e}$, na camada de $0,20-0,40 \mathrm{~m}$ : matéria orgânica $=$ $22 \mathrm{~g} \mathrm{dm}^{-3}, \mathrm{pH}\left(0,01 \mathrm{~mol} \mathrm{~L}^{-1} \mathrm{CaCl}_{2}\right)=3,9, \mathrm{P}($ resina $)=6 \mathrm{mg}$ $\mathrm{dm}^{-3}, \mathrm{~K}, \mathrm{Ca}, \mathrm{Mg}, \mathrm{Al}^{3+}$ e CTC $=0,2,18,5,18$ e $105 \mathrm{mmol}_{\mathrm{c}}$ $\mathrm{dm}^{-3}$, respectivamente, $\mathrm{V}=22 \%$ e teores de areia, silte e argila, respectivamente, de 513, 127 e $360 \mathrm{~g} \mathrm{~kg}^{-1}$.
O delineamento experimental utilizado foi em blocos casualizados em esquema de parcelas subsubdivididas, com quatro repetições. Nas parcelas $(5,4$ x 18,0 m) os tratamentos foram quatro doses de calcário dolomítico $\left(0,1.100,2.700\right.$ e $\left.4.300 \mathrm{~kg} \mathrm{ha}^{-1}\right)$, com $23,3 \%$ de $\mathrm{CaO}, 17,5 \%$ de $\mathrm{MgO}$ e $71 \%$ de PRNT, calculadas visando elevar a saturação por bases para $50 \%, 70 \%$ e $90 \%$ respectivamente. Nas subparcelas $(5,4 \times 9,0 \mathrm{~m})$, os tratamentos foram aplicação ou não de $2.100 \mathrm{~kg} \mathrm{ha}^{-1}$ de gesso agrícola ( $20 \%$ de Ca e $16 \%$ de S), calculado multiplicando-se o teor de argila na camada de 0,20-0,40 $\mathrm{m}$ de profundidade, $360 \mathrm{~g} \mathrm{~kg}^{-1}$, por seis. Foram mantidas distâncias de $8,0 \mathrm{~m}$ entre as parcelas dentro de cada bloco e de $3,0 \mathrm{~m}$ entre os blocos. Nas sub-subparcelas $(2,7 \times 9,0 \mathrm{~m})$, os tratamentos foram duas cultivares de arroz de terras altas (Caiapó e IAC 202), no ano agrícola 
2002/2003, e em sucessão, por dois de feijão (Pérola e Carioca), no ano agrícola de 2003/ 2004.

Acv. Caiapó de arroz de terras altasé recomendada para solos de baixa fertilidade, em situações de abertura de áreas e reforma de pastagens degradadas. A cv. IAC 202 é de baixa tolerância à toxidez de $\mathrm{Al}^{3+} \mathrm{e} \mathrm{Fe}^{3+}$, sendo comprometido seu desenvolvimento em solos de baixa fertilidade. Acv. Carioca de feijãoé considerada de ampla adaptabilidade ambiental e estabilidade de produção, portanto, mais rústica e tolerante às condições de acidez do solo. A cv. Pérola é considerada de alto potencial produtivo e a mais cultivada atualmente no Brasil. Segundo SiLva (2002), em condições de elevada acidez do solo, a cultivar Carioca possui maior capacidade de absorção e transporte de N, P, K, Ca, Mg e Zn que a cultivar Pérola.

O calcário foi aplicado sobre os restos culturais de guandu (7.400 kg ha-1 de matéria seca) em 15/10/2002. Em 16/10/2002, aplicou-se o gesso agrícola nas subparcelas, e tanto o calcário quanto o gesso foram aplicados a lanço e sem incorporação ao solo.

Em 20/11/2002 foi realizada a semeadura das cultivares de arroz, com aproximadamente 70 sementes por metro linear, em espaçamento entrelinhas de 0,30 $\mathrm{m}$. A adubação nos sulcos de semeadura constituiu-se de $24 \mathrm{~kg} \mathrm{ha}^{-1}$ de $\mathrm{N}, 84$ de $\mathrm{P}_{2} \mathrm{O}_{5^{\prime}} 48$ de $\mathrm{K}_{2} \mathrm{O}, 13,5$ de $\mathrm{S}$ e 1,5 de Zn (300 kg ha-1 da fórmula 08-28-16 + 4,5\% de $\mathrm{S}+0,5 \%$ de $\mathrm{Zn}$ ). Como adubação de cobertura foram aplicados $50 \mathrm{~kg} \mathrm{ha}^{-1}$ de $\mathrm{N}$ na forma de uréia, aos 45 DAE (perfilhamento). Em 6/1/2004 foi realizada a semeadura do feijão, com aproximadamente 18 sementes por metro linear, em espaçamento entre linhas de 0,45 m. A adubação nos sulcos de semeadura foi igual à utilizada no ano anterior para o arroz. As adubações de cobertura foram realizadas em 22 e $10 / 2 / 2004$, quando as plantas estavam com a terceira folha trifoliolada expandida $\left(V_{4}\right)$ e em pré-floração $\left(R_{5}\right)$, aplicando-se, respectivamente, 70 e $40 \mathrm{~kg} \mathrm{ha}^{-1}$ de $\mathrm{N}$ na forma de nitrato de amônio. No inverno de 2003, foi cultivada em toda a área experimental a aveia preta (Avena strigosa Schreber), cv. Comum, com produção de matéria seca média de $4.879 \mathrm{~kg} \mathrm{ha}^{-1}$.

O florescimento das cultivares de arroz ocorreu em 5/3/2003 (IAC 202) e 14/3/2003 (Caiapó) e das cultivares de feijão em $20 / 2 / 2004$.

Foram determinados os componentes da produção das culturas do arroz (número de panículas por $\mathrm{m}^{2}$, número de espiguetas por panículas, fertilidade das espiguetas e massa de mil grãos) e do feijão (população final de plantas, número de vagens por planta, número de grãos por vagem e massa de cem grãos), mediante a avaliação de $2 \mathrm{~m}$ de linha (arroz) e 10 plantas (feijão) na área útil de cada sub-subparcela.
A produtividade de grãos foi avaliada na área útil de cada sub-subparcela e ajustada para $130 \mathrm{~g} \mathrm{~kg}^{-1} \mathrm{de}$ umidade.

Os resultados foram submetidos à análise de variância. As médias referentes à aplicação de gesso e às cultivares foram comparadas pelo teste $t$ (DMS) a 5\% de probabilidade, enquanto os efeitos das doses de calcário foram avaliados por meio de análise de regressão, adotando-se como critério para escolha do modelo, a magnitude dos coeficientes de regressão significativos ao nível de 5\% de probabilidade pelo teste $t$. Foram realizadas análises de correlação simples entre os componentes da produção e a produtividade de grãos.

\section{RESULTADOS E DISCUSSÃO}

$\mathrm{Na}$ cultura do arroz, verificou-se influência das interações calcário x gesso, calcário x cultivar e gesso $x$ cultivar no número de panículas por $\mathrm{m}^{2}$ (Tabela 1). A calagem, tanto na presença, quanto na ausência de gesso, promoveu efeito quadrático no número de panículas $\mathrm{m}^{-2}$ (Tabela 2). Ambas as cultivares de arroz foram responsivas à aplicação de calcário em superfície de forma quadrática, porém, a cultivar Caiapó foi responsiva a doses mais elevadas (Tabela 3). Mediante o desdobramento da interação cultivar $x$ gesso, verificou-se que no tratamento sem aplicação de gesso a cultivar IAC 202 se destacou; já com a aplicação de gesso o inverso ocorreu, com o maior número de panícula por $\mathrm{m}^{2}$ sendo apresentado por 'Caiapó' (Tabela 2). O maior número de panículas, na cultivar Caiapó, proporcionado pela aplicação de gesso, provavelmente, é resultado do maior crescimento radicular decorrente deste tratamento. Como observado por SORATto (2005), nesse mesmo ensaio, esse fatodeve ter possibilitado maior absorção de água nos períodos de deficiência hídrica que ocorreram na fase reprodutiva (Figura 1). SORATTO e CRUSCiOl (2008a, b) verificaram que a aplicação de gesso aumentou a disponibilidade de $\mathrm{Ca}$ e $\mathrm{S}$ e reduziu o teor de $\mathrm{Al}$ tóxico no solo. Como o período de estiagem não foi longo e o efeito da deficiência hídrica foi agravado mais pela alta demanda evapotranspirativa do que pela falta d'água no solo, o aumento no crescimento radicular, mesmo que nas camadas superficiais, pode ter contribuído para aumentar a tolerância da cultivar Caiapó à deficiência hídrica.

No que se refere ao número de espiguetas por panícula, verifica-se que houve efeito do fator cultivar e das interações calcário $\mathrm{x}$ gesso e calcário $\mathrm{x}$ cultivar (Tabela 1). Apenas na ausência de gesso, a calagem incrementou o número de espiguetas por panícula, de forma quadrática (Tabela 2), sem promover efeito na presença de gesso. A cultivar IAC 202 foi responsiva 
Tabela 1. Componentes da produção e produtividade de grãos de arroz de terras altas em função da aplicação de gesso e de cultivares, num Latossolo Vermelho distroférrico, em fase de implantação do SPD. Ano agrícola de 2002/ 2003

\begin{tabular}{|c|c|c|c|c|c|}
\hline Tratamentos & Panículas $\mathrm{m}^{-2}$ & Espiguetas panícula $^{-1}$ & Fertilidade das espiguetas & Massa de mil grãos & Grãos \\
\hline Gesso & $\ldots$ & $\mathrm{n} .^{\circ}$ & $\%$ & $\mathrm{~g}$ & $\mathrm{~kg} \mathrm{ha}^{-1}$ \\
\hline Sem & $127,3 \mathrm{a}$ & $96,7 \mathrm{a}$ & $56,3 \mathrm{a}$ & $19,6 \mathrm{a}$ & $1.346 \mathrm{a}$ \\
\hline Com & $120,5 \mathrm{a}$ & $99,8 \mathrm{a}$ & $54,6 \mathrm{a}$ & $19,6 \mathrm{a}$ & $1.485 \mathrm{a}$ \\
\hline \multicolumn{6}{|l|}{ Cultivar } \\
\hline Caiapó & $126,7 \mathrm{a}$ & $78,9 \mathrm{~b}$ & $81,2 \mathrm{a}$ & $21,2 \mathrm{a}$ & $1.892 \mathrm{a}$ \\
\hline IAC 202 & $121,1 \mathrm{a}$ & $117,5 \mathrm{a}$ & $49,6 b$ & $18,0 \mathrm{~b}$ & $938 b$ \\
\hline \multicolumn{6}{|l|}{ Significância } \\
\hline Calcário (Cal) & ns & ns & ns & ns & $*$ \\
\hline Gesso (Ges) & ns & ns & ns & ns & ns \\
\hline Cal x Ges & $* *$ & $*$ & ns & ns & ns \\
\hline Cultivar (Cul) & ns & $* *$ & $*$ & ns & $* *$ \\
\hline Cal x Cul & $* *$ & $*$ & $\mathrm{~ns}$ & $*$ & $* *$ \\
\hline Ges x Cul & $* *$ & ns & ns & ns & $* *$ \\
\hline Cal x Ges x Cul & ns & ns & ns & ns & ns \\
\hline $\mathrm{CV}_{\text {parcela }}(\%)$ & 18,5 & 8,2 & 16,8 & 5,7 & 28,3 \\
\hline $\mathrm{CV}_{\text {subparcela }}(\%)$ & 14,0 & 13,7 & 9,2 & 2,3 & 9,6 \\
\hline $\mathrm{CV}_{\text {sub-subparcelas }}(\%)$ & 12,1 & 16,4 & 15,2 & 5,7 & 14,4 \\
\hline
\end{tabular}

Médias seguidas de letras distintas, na coluna, dentro de cada fator (gesso e cultivar) diferem estatisticamente pelo teste de $t$ $(\mathrm{P}=0,05) . \mathrm{ns},{ }^{*},{ }^{* *}$ : não-significativo e significativos a $5 \%$ e $1 \%$ pelo teste $\mathrm{F}$ respectivamente.

Tabela 2. Desdobramento das interações calcário x gesso, referente ao número de panículas por $\mathrm{m}^{2}$ e de espiguetas por panícula, e gesso x cultivar, referente ao número de panículas por $\mathrm{m}^{2}$ e produtividade de grãos de arroz de terras altas, em Latossolo Vermelho distroférrico, em fase de implantação do SPD. Ano agrícola de 2002/ 2003

\begin{tabular}{|c|c|c|c|c|c|c|}
\hline \multirow{2}{*}{ Gesso } & \multicolumn{4}{|c|}{ Calcário $\left(\mathrm{kg} \mathrm{ha}^{-1}\right)$} & \multirow{2}{*}{ Regressão } & \multirow{2}{*}{$\mathrm{R}^{2}$} \\
\hline & 0 & 1.100 & 2.700 & 4.300 & & \\
\hline \multirow[b]{2}{*}{ Sem } & & & & $-\mathrm{N}$. & 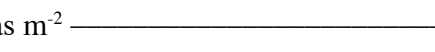 & - \\
\hline & $111,1 \mathrm{a}$ & $156,3 a$ & $129,3 \mathrm{~b}$ & $112,6 \mathrm{a}$ & $\hat{y}=102,43+0,026 x-0,000007 x^{2}$ & $0,65^{* *}$ \\
\hline \multirow[t]{2}{*}{ Com } & $118,1 \mathrm{a}$ & $94,0 \mathrm{~b}$ & $157,4 \mathrm{a}$ & $112,6 b$ & $\hat{y}=91,39+0,019 x-0,000004 x^{2}$ & $0,19 *$ \\
\hline & & & & N. ${ }^{\circ}$ de & anículas ${ }^{-1}$ & \\
\hline Sem & $90,9 \mathrm{a}$ & $104,5 \mathrm{a}$ & $99,5 \mathrm{a}$ & $83,7 \mathrm{~b}$ & $\hat{y}=91,86+0,014 x-0,000004 x^{2}$ & $0,96^{* *}$ \\
\hline \multirow[t]{3}{*}{ Com } & $96,2 \mathrm{a}$ & $89,8 \mathrm{a}$ & $97,9 \mathrm{a}$ & $99,2 \mathrm{a}$ & - & ns \\
\hline & \multicolumn{6}{|c|}{ Cultivar } \\
\hline & \multicolumn{4}{|c|}{ Caiapó } & IAC 202 & \\
\hline & - & 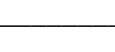 & -1 & \multirow[t]{3}{*}{ ulas $\mathrm{m}^{-2} \longrightarrow$} & \\
\hline Sem & \multicolumn{4}{|c|}{$118,8 \mathrm{bB}$} & & \\
\hline Com & \multicolumn{4}{|c|}{$134,5 \mathrm{aA}$} & & \\
\hline Sem & \multicolumn{4}{|c|}{$1.721 \mathrm{bA}$} & \multicolumn{2}{|l|}{$970 \mathrm{aB}$} \\
\hline Com & \multicolumn{4}{|c|}{$2.064 \mathrm{aA}$} & $906 \mathrm{aB}$ & \\
\hline
\end{tabular}

Médias seguidas de letras distintas, minúscula na coluna e maiúscula na linha, para cada variável, diferem estatisticamente pelo teste de $\mathrm{t}(\mathrm{P}=0,05) . \mathrm{ns}{ }^{*}$ : não-significativo e significativos a $5 \%$ pelo teste $\mathrm{F}$ respectivamente. 
Tabela 3. Desdobramento da interação calcário x cultivar da análise da variância referente ao número de panículas por $\mathrm{m}^{2}$ e de espiguetas por panícula, massa de mil grãos e produtividade de grãos de arroz de terras altas, em um Latossolo Vermelho distroférrico, em fase de implantação do SPD. Ano agrícola de 2002 / 2003

\begin{tabular}{|c|c|c|c|c|c|c|}
\hline \multirow{2}{*}{ Cultivar } & \multicolumn{4}{|c|}{ Calcário $\left(\mathrm{kg} \mathrm{ha}^{-1}\right)$} & \multirow{2}{*}{ Regressão } & \multirow{2}{*}{$\mathrm{R}^{2}$} \\
\hline & 0 & 1.100 & 2.700 & 4.300 & & \\
\hline \multicolumn{7}{|c|}{ - N..$^{\circ}$ de panículas $\mathrm{m}^{-2}$} \\
\hline Caiapó & $114,1 \mathrm{a}$ & $116,7 b$ & $150,9 \mathrm{a}$ & $125,2 \mathrm{a}$ & $\hat{y}=94,35+0,021 x-0,000004 x^{2}$ & $0,62 *$ \\
\hline \multirow[t]{2}{*}{ IAC 202} & $115,0 \mathrm{a}$ & $133,5 \mathrm{a}$ & $135,8 \mathrm{a}$ & $99,9 b$ & $\hat{y}=99,38+0,023 x-0,000006 x^{2}$ & $0,99 * *$ \\
\hline & & & & $-\mathrm{N} .^{\circ} \mathrm{de}$ & panículas ${ }^{-1}$ & \\
\hline Caiapó & $77,2 \mathrm{~b}$ & $69,5 \mathrm{~b}$ & $73,4 \mathrm{~b}$ & $71,8 b$ & ns & \\
\hline \multirow[t]{2}{*}{ IAC 202} & $109,8 \mathrm{a}$ & $124,8 \mathrm{a}$ & $124,1 \mathrm{a}$ & $111,2 \mathrm{a}$ & $\hat{y}=110,54+0,016 x-0,000004 x^{2}$ & $0,97 * *$ \\
\hline & & & & _- Mass & rãos $(\mathrm{g})$ & - \\
\hline Caiapó & $20,9 \mathrm{a}$ & $20,7 \mathrm{a}$ & $21,5 \mathrm{a}$ & $21,6 a$ & $\hat{y}=20,78+0,0002 x$ & $0,78^{*}$ \\
\hline IAC 202 & $17,8 \mathrm{~b}$ & $18,0 \mathrm{~b}$ & $18,7 \mathrm{~b}$ & $17,6 b$ & $\hat{y}=17,63+0,0008 x-0,0000002 x^{2}$ & $0,78^{*}$ \\
\hline Caiapó & $1.648 \mathrm{a}$ & $1.621 \mathrm{a}$ & $2.042 \mathrm{a}$ & $2.259 \mathrm{a}$ & $\left.h^{-1}\right)-\hat{y}=1570,8+0,1589 x$ & $0,92 * *$ \\
\hline IAC 202 & $662 b$ & $899 b$ & $1.205 b$ & $987 b$ & $\hat{y}=634+0,372 x-0,00007 x^{2}$ & $0,95 *$ \\
\hline
\end{tabular}

Médias seguidas de letras distintas, na coluna, para cada variável, diferem estatisticamente pelo teste de $\mathrm{t}(\mathrm{P}=0,05)$. $\mathrm{ns},{ }^{*},{ }^{* *}$ : não-significativo e significativos a $5 \%$ e $1 \%$ pelo teste $\mathrm{F}$ respectivamente.

à calagem de forma quadrática, visto que não houve efeito da calagem no número de espiguetas por panícula na cultivar Caiapó (Tabela 3); além disso, essa cultivar proporcionou menor número médio de espiguetas por panícula em relação ao IAC 202 (Tabela 1).

Para a variável fertilidade das espiguetas foi observado efeito apenas de cultivar (Tabela 1), e Caiapó obteve os maiores valores, pelo fato de o florescimento ter ocorrido em um período com menor deficiência hídrica (Figura 1). A ocorrência de deficiência hídrica durante a meiose da célula mãe do grão de pólen, no período de 11 a 3 dias que antecedem o florescimento (YoshidA, 1977), reduz o número de espigueta granadas por panícula.

A massa de mil grãos foi influenciada pela interação calcário x cultivar (Tabela 1). A cultivar Caiapó foi responsiva de forma linear, tendo acréscimos na massa de mil grãos com o aumento das doses de calcário em superfície (Tabela 3). A cultivar IAC 202 respondeu de forma quadrática, com a maior massa de mil grãos e dose máxima estimada de 2.000 $\mathrm{kg} \mathrm{ha}^{-1}$ de calcário.

A produtividade de grãos foi influenciada pelos fatores calcário e cultivar e pelas interações calcário $x$ cultivar e gesso x cultivar (Tabela 1). Pelo desdobramento da interação cultivar x gessagem, verifica-se que a cultivar IAC 202 teve produtividade inferior à cultivar Caiapó e a aplicação de gesso promoveu incremento significativo na produtividade de grãos da cultivar Caiapó (Tabela 2). Destaca-se que os efeitos observados na produtividade de grãos foram semelhantes aos observados para o número de panícula $\mathrm{m}^{-2}$, explicado pela correlação significativa entre estas variáveis $(r=$ $0,53 ; \mathrm{p}<0,01)$.

O aumento das doses de calcário promoveu incremento linear na produtividade de grãos da cultivar Caiapó, e com a aplicação da maior dose (4.300 $\mathrm{kg} \mathrm{ha}^{-1}$ ) observou-se produtividade de $2.259 \mathrm{~kg} \mathrm{ha}^{-1}$ (Tabela 3). Esse resultado é explicado pelas correlações significativas da produtividade de grãos com o número de panículas $\mathrm{m}^{-2}(\mathrm{r}=0,77 ; \mathrm{p}<0,001)$ e a massa de mil grãos $(\mathrm{r}=0,50 ; \mathrm{p}<0,01)$, uma vez que ambos os componentes da produção aumentaram com o incremento das doses de calcário em superfície.

A cultivar IAC 202 respondeu de forma quadrática aos aumentos na dose de calcário, tendo produtividade máxima com a dose calculada de $2.520 \mathrm{~kg} \mathrm{ha}^{-1}$ de calcário (Tabela 3). $\mathrm{O}$ aumento da produtividade até a dose de calcário calculada é explicada pelas correlações significativas da produtividade de grãos com o número de panículas $\mathrm{m}^{-2}(\mathrm{r}=0,59 ; v<0,001)$ e a massa de mil grãos $(r=0,42 ; p<0,05)$. Neste trabalho, ficou evidente que a calagem em superfície aumenta a produtividade de grãos da cultura do arroz de terras altas, por incrementar, principalmente os componentes: número de panículas $\mathrm{m}^{-2} \mathrm{e}$ massa de mil grãos. Esse parecer é de relevada importância, pois os trabalhos com corretivos e condicionadores de solo raramente revelam informações sobre qual dos componentes da produção é influenciado positivamente pela calagem e que explicam o aumento da produtividade de grãos. 
A menor produtividade de grãos, bem como, os menores valores dos componentes da produção da cultivar IAC 202, obtidos com a aplicação da dose de calcário para elevar a $\mathrm{V}$ a $90 \%$, em comparação à dose para elevar a $\mathrm{V}$ a $70 \%$, não está relacionada à redução da disponibilidade dos micronutrientes catiônicos no solo, posto que as concentrações foliares de $\mathrm{Cu}, \mathrm{Fe}, \mathrm{Mn}$ e $\mathrm{Zn}$, foram em média de 6,1,63,8, 237,0 e 17,5 mg kg-1 respectivamente (SORATTO e CRUSCIOL, 2008b). A calagem pouco alterou os teores desses nutrientes no solo (Soratto e Crusciol, 2008a). Em todos os tratamentos as concentrações estavam dentro da faixa considerada adequada (CANTARELla et al., 1996), com exceção do Fe, cujos valores ficaram abaixo dessa faixa. De acordo com FAGERIA (1982), FERREIRA et al. (1986) e DuARTE et al. (1999), existem diferenças entre as cultivares de arroz quanto às suas respostas ao alumínio no solo e à calagem, apesar do arroz ser uma espécie adaptada às condições de acidez do solo (FAGERIA, 2000; DuARTE et al., 1999).

A cultivar Caiapó proporcionou maior produtividade mesmo no tratamento sem aplicação de corretivo (Tabelas 1 e 3), o que pode ser explicado por ser uma cultivar mais tolerante à acidez, em comparação com IAC 202. Contudo, todos os tratamentos tiveram baixa produtividade de grãos, justificada pela ocorrência de períodos de estiagem (veranicos) e altas temperaturas entre o início da fase reprodutiva (diferenciação floral) e o florescimento das cultivares (Figura 1). Assim, a cultivar IAC 202 foi mais afetada pela deficiência hídrica, com fertilidade das espiguetas muito menor que Caiapó, que floresceu em um período sem déficit de água. A deficiência hídrica no período de 3 a 11 dias que antecedem o florescimento reduz o número de espiguetas granadas por panícula (YoshIDA, 1977).

A população final de plantas da cultura do feijão não foi afetada de forma significativa pelos tratamentos (Tabela 4).

Quanto ao número de vagens por planta verificouse efeito da cultivar e das interações calcário $x$ gesso e gesso x cultivar (Tabela 4). Na ausência de gesso, as doses de calcário afetaram o número de vagens por planta, com efeito quadrático (Tabela 5). Mediante o desdobramento da interação gesso x cultivar (Tabela 5), verificou-se, na cultivar Carioca, na ausência de gesso, maior número de vagens por planta, não diferindo da cultivar Pérola com presença de gesso. Nessa cultivar também se notou redução no número de vagens por planta com a aplicação de gesso agrícola em superfície. Os resultados indicam que a cultivar Carioca possui maior tolerância às condições de acidez e menor teor de Ca no solo, como foi observado por SILVA (2002), principalmente, devido ao seu maior e mais bem distribuído sistema radicular (SORATTO, 2005).

Tabela 4. População de plantas, componentes da produção e produtividade de grãos de feijão em função de gesso e de cultivares, num Latossolo Vermelho distroférrico, em fase de implantação do SPD. Ano agrícola de 2003/ 2004

\begin{tabular}{|c|c|c|c|c|c|}
\hline Tratamentos & População de plantas & Vagens por planta & Grãos por vagem & Massa de 100 grãos & Grãos \\
\hline Gesso & mil plantas ha ${ }^{-1}$ & $\mathrm{n}^{\circ}$ & + & $\mathrm{g}$ & $\mathrm{kg} \mathrm{ha}^{-1}$ \\
\hline Sem & $288 \mathrm{a}$ & $8,0 \mathrm{a}$ & $3,6 \mathrm{a}$ & $28,4 \mathrm{a}$ & $2.328 \mathrm{a}$ \\
\hline Com & $300 a$ & $7,7 \mathrm{a}$ & $3,6 a$ & $28,5 \mathrm{a}$ & $2.369 \mathrm{a}$ \\
\hline \multicolumn{6}{|l|}{ Cultivar } \\
\hline Carioca & $287 \mathrm{a}$ & $8,9 \mathrm{a}$ & $4,2 \mathrm{a}$ & $25,9 \mathrm{~b}$ & $2.679 \mathrm{a}$ \\
\hline Pérola & $301 \mathrm{a}$ & $6,8 \mathrm{~b}$ & $3,1 b$ & $30,7 \mathrm{a}$ & $2.019 \mathrm{~b}$ \\
\hline \multicolumn{6}{|l|}{ Significância } \\
\hline Calcário (Cal) & ns & ns & ns & ns & ns \\
\hline Gesso (Ges) & ns & ns & ns & $\mathrm{ns}$ & $\mathrm{ns}$ \\
\hline Cal x Ges & ns & $*$ & ns & ns & $*$ \\
\hline Cultivar (Cul) & $\mathrm{ns}$ & $*$ & $*$ & $* *$ & $*$ \\
\hline Cal x Cul & ns & ns & ns & ns & ns \\
\hline Ges x Cul & ns & $*$ & ns & ns & ns \\
\hline Cal x Ges x Cul & ns & ns & ns & ns & ns \\
\hline $\mathrm{CV}_{\text {parcela }}(\%)$ & 5,5 & 28,8 & 14,1 & 3,9 & 22,3 \\
\hline $\mathrm{CV}_{\text {subparcela }}(\%)$ & 7,8 & 12,8 & 6,6 & 3,6 & 7,6 \\
\hline $\mathrm{CV}_{\text {sub-subparcelas }}(\%)$ & 7,0 & 22,3 & 8,7 & 4,0 & 9,1 \\
\hline
\end{tabular}

Médias seguidas de letras distintas, na coluna, dentro de cada fator (gesso e cultivar), diferem estatisticamente pelo teste de $\mathrm{t}$ a $5 \%$ de probabilidade. $\mathrm{ns},{ }^{*},{ }^{* *}$ : não-significativo e significativos a $5 \%$ e $1 \%$ pelo teste $\mathrm{F}$, respectivamente. 
Tabela 5. Desdobramento das interações calcário x gesso, referente a número de vagens por planta e produtividade de grãos, e gesso x cultivar, referente ao número de vagens por planta de feijão, num Latossolo Vermelho distroférrico, em fase de implantação do SPD. Ano agrícola de 2003/2004 ${ }^{(1)}$

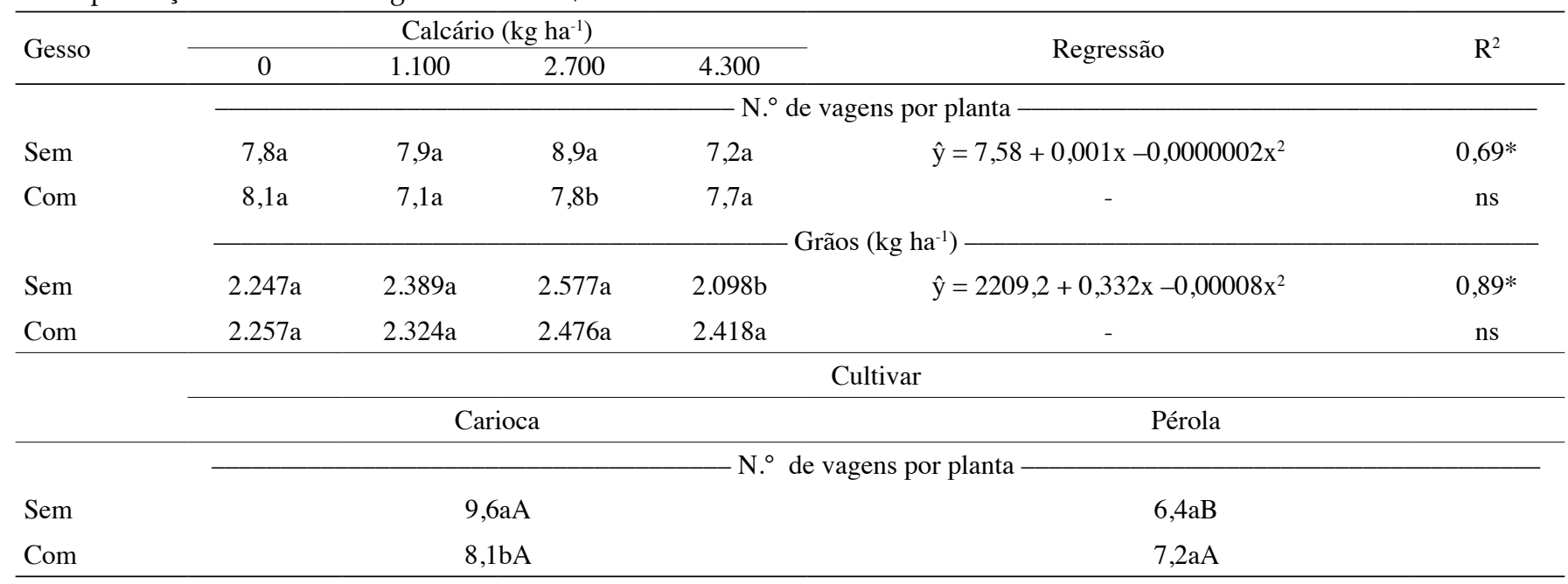

Médias seguidas de letras distintas, minúscula na coluna e maiúscula na linha, para cada variável, diferem estatisticamente pelo teste de $\mathrm{t}(\mathrm{P}=0,05)$. ns, * : não-significativo e significativos a $5 \%$ pelo teste $\mathrm{F}$ respectivamente.

Onúmero de grãos por vagem não foi influenciado pela aplicação de calcário e gesso (Tabela 4). MorAEs et al. (1998), trabalhando com incorporação dos corretivos, também não verificaram efeito da calagem e da gessagem nessa característica do feijoeiro, cultivar Carioca-80. A cultivar Carioca proporcionou maior número de grãos por vagem (Tabela 4), uma característica de alta herdabilidade genética, pouco influenciada pelo ambiente.

A massa de cem grãos foi afetada apenas pela cultivar, porém em Pérola, observaram-se os maiores valores (Tabela 5). MoraEs et al. (1998) também não verificaram efeito da aplicação de calcário e gesso incorporado ao solo, na massa dos grãos do feijoeiro.

A produtividade foi influenciada pela cultivar e pela interação calcário e gesso (Tabela 4). A cultivar Carioca proporcionou maior produtividade de grãos. Esse resultado está associado à sua maior capacidade de absorção de nutrientes, provavelmente devido ao seu sistema radicular mais vigoroso (SORATTO, 2005).

Refletindo o que foi observado para o número de vagens por planta, a calagem, na ausência da aplicação de gesso, promoveu aumento na produtividade de grãos, com os dados sendo ajustados a uma função quadrática, sendo a produtividade máxima obtida com a dose calculada de $2.075 \mathrm{~kg} \mathrm{ha}^{-1}$ de calcário (Tabela 5). O número de vagens por planta foi o componente da produção que mais se correlacionou com a produtividade de grãos $(\mathrm{r}=0,68 ; \mathrm{p}<0,001)$, sendo o mais influenciado pelas condições ambientais, entre elas a acidez do solo. Assim, a redução da acidez e a elevação na saturação por bases proporcionada pela aplicação de calcário, na ausência de gesso, principalmente nas camadas de 0,05-0,10 e 0,10-0,20 m (SorATto e Crusciol, 2008a), favoreceram a adequada nutrição das cultivares de feijão (SORATTO e CRUSCIOL, 2008b). A aplicação da maior dose de calcário, na ausência de gesso, porém, proporcionou redução na produtividade de grãos do feijoeiro, em comparação com o tratamento que também recebeu gesso, a exemplo do que ocorreu com a concentração de $S$ nas folhas (SORATTO e CRUSCIOL, 2008b), o que pode estar relacionado com o menor teor de $\mathrm{S}_{-} \mathrm{SO}_{4}{ }^{2-}$ nas camadas superficiais do solo, proporcionado por esse tratamento (Soratto e CRusciol, 2008a). De acordo com Portes (1996), o feijoeiro com deficiência nutricional produz menos flores e, consequentemente, menos vagens por planta do que sem deficiência, o que influencia diretamente a produtividade de grãos. Vale destacar que as concentrações médias de $\mathrm{Cu}, \mathrm{Fe}, \mathrm{Mn}$ e $\mathrm{Zn}$ nas folhas do feijoeiro, que foram, respectivamente, de 13,9, 268,5, 86,7 e $26 \mathrm{mg} \mathrm{kg}^{-1}$ (Soratto e Crusciol, 2008b), estavam, exceção do $\mathrm{Fe}$, com concentrações elevadas, na faixa considerada adequada por AMBROSANO et al. (1996), em todos os tratamentos.

\section{CONCLUSÕES}

1. O número de panículas por $\mathrm{m}^{2}$, o número de espiguetas por panícula, a massa de mil grãos e a produtividade de grãos das cultivares de arroz de terras altas, são incrementados pela aplicação de calcário em superfície na implantação do SPD.

2. A aplicação de gesso aumenta o número de panículas por $\mathrm{m}^{2}$ e a produtividade da cultivar 
Caiapó, mas reduz o número de panículas e não afeta a produtividade da cultivar IAC 202 de arroz.

3. A calagem, na ausência de gesso, promove aumento do número de vagens por planta e da produtividade de grãos das cultivares de feijão.

4. A aplicação de gesso reduz o número de vagens por planta da cultivar Carioca de feijão, mas não altera outros componentes da produção e a produtividade da cultura.

5. Na implantação do SPD, a dose de calcário para elevar a saturação por bases a $70 \%$ é a mais adequada para ambas as culturas.

6. O uso de cultivares mais tolerantes à acidez do solo proporciona a obtenção de maiores produtividades das culturas no início do SPD, quando ainda não houve efetiva correção do solo pela aplicação de corretivos em superfície.

\section{AGRADECIMENTOS}

À FAPESP pelo auxílio financeiro e pela concessão de bolsas ao primeiro e terceiro autores.

\section{REFERÊNCIAS}

ADAMS, F.; LUND, Z.F. Effects of chemical activity of soil solution aluminum on cotton root penetration of acid subsoils. Soil Science, v.101, p.193-198, 1966.

AMBROSANO, E.J.; TANAKA, R.T.; MASCARENHAS, H.A.A.; RAIJ, B. van; QUAGGIO, J.A.; CANTARELLA, H. Leguminosas e oleaginosas. In: RAIJ, B. van; CANTARELLA, H.; QUAGGIO, J.A.; FURLANI, A.M.C. (Ed.). Recomendações de adubação e calagem para o Estado de São Paulo. 2.ed. Campinas: Instituto Agronômico, 1996, p.187-202. (Boletim Técnico 100)

BALBINO, L.C.; MOREIRA, J.A.A.; SILVA, J.G.; OLIVEIRA, E.F.; OLIVEIRA, I.P. Plantio direto. In: ARAUJO, R.S.; RAVA, C.A.; STONE, L.F.; ZIMMERMANN, M.J.O. (Coord.). Cultura do feijoeiro comum no Brasil. Piracicaba: Potafós, 1996. p.301-352.

CAIRES, E.F.; ALLEONI, L.R.F.; CAMBRI, M.A.; BARTH, G. Surface application of lime for crop grain prodution under a no-till system. Agronomy Journal, v.97, p.791-798, 2005.

CAIRES, E.F.; BLUM, J.; BARTH, G. GARBUIO, F.J.; KUSMAN, M.T. Alterações químicas do solo e resposta da soja ao calcário e gesso aplicados na implantação do sistema de plantio direto. Revista Brasileira de Ciência do Solo, v.27, p.275-286, 2003.

CAIRES, E.F.; KUSMAN, M.T.; BARTH, G.; GARBUIO, F.J.; PADILHA, J.M. Alterações químicas do solo e resposta do milho à calagem e aplicação de gesso. Revista Brasileira de Ciência do Solo, v.28, p.125-136, 2004.
CANTARELLA, H.; RAIJ, B. van; CAMARGO, C.E.O. Cereais. In: RAIJ, B. van; CANTARELLA, H.; QUAGGIO, J.A.; FURLANI, A.M.C. (Ed.). Recomendações de adubação e calagem para o Estado de São Paulo. 2.ed. Campinas: Instituto Agronômico, 1996, p.45-71. (Boletim Técnico 100)

DUARTE, A.P.; QUEIROZ-VOLTAN, R.B.; FURLANI, P.R.; KANTHACK, R.A.D. Resposta de cultivares de arroz-desequeiro à calagem. Bragantia, v.58, p.353-361, 1999.

FAGERIA, N.K. Resposta de arroz de terras altas à correção de acidez em solo de cerrado. Pesquisa Agropecuária Brasileira, v.35, p.2303-2307, 2000.

FAGERIA, N.K. Tolerância diferencial de cultivares de arroz ao alumínio em solução nutritiva. Pesquisa Agropecuária Brasileira, v.17, p.1-9, 1982.

FERREIRA, R.P.; SALGADO, L.T.; JORGE, H.D. Tolerância de cultivares de arroz ao alumínio. Pesquisa Agropecuária Brasileira, v.21, p.1257-1260, 1986.

FORNASIERI FILHO, D.; FORNASIERI, J.L. Manual da cultura do arroz. Jaboticabal: Funep, 1993. 220p.

MORAES, J.F.L.; BELLINGIERI, P.A.; FORNASIERI FILHO, D.; GALON, L.A. Efeitos de doses de calcário e de gesso na cultura do feijoeiro (Phaseolus vulgaris L.) cv. Carioca-80. Scientia Agricola, v.55, p.75-82, 1998.

PAVAN, M.A.; OLIVEIRA, E.L. Corretivos da acidez do solo: experiências no Paraná. In: KAMINSKI, J. (Coord.). Uso de corretivos da acidez do solo no plantio direto. Pelotas: Núcleo Regional Sul da Sociedade Brasileira de Ciência do Solo, 2000. p.61-76. (Boletim, 4)

PIRES, F.R.; SOUZA, C.M.; QUEIROZ, D.M.; MIRANDA, G.V.; GALVÃO, J.C. Alterações de atributos químicos do solo e estado nutricional e características agronômicas de plantas de milho, considerando as modalidades de calagem em plantio direto. Revista Brasileira de Ciência do Solo, v.27, p.121-131, 2003.

PORTES, T.A. Ecofisiologia. In: ARAÚJO, R.S.; RAVA, C.A.; STONE, L.F.; ZIMMERMANN, M.J.O. (Coord.). Cultura do feijoeiro comum no Brasil. Piracicaba: Potafos, 1996. p.101137.

QUAGGIO, J.A.; RAIJ, B. van; GALLO, P.B.; MASCARENHAS, H.A.A. Resposta da soja à aplicação de calcário e gesso e lixiviação de íons no perfil do solo. Pesquisa Agropecuária Brasileira, v.28, p.375-383, 1993.

RAIJ, B. van; ANDRADE, J.C.; CANTARELLA, H.; QUAGGIO, J.A. Análise química para avaliação da fertilidade de solos tropicais. Campinas: Instituto Agronômico, 2001. 284p.

SILVA, L.M. Crescimento radicular e nutrição mineral de cultivares de feijão em resposta à calagem. 2002. 70f. Dissertação (Mestrado em Agronomia/Agricultura) Faculdade de Ciências Agronômicas, Universidade Estadual Paulista, Botucatu. 
SORATTO, R.P. Aplicação de calcário e gesso em superfície na implantação do sistema de plantio direto. 2005. 173f. Tese (Doutorado em Agronomia/Agricultura) - Faculdade de Ciências Agronômicas, Universidade Estadual Paulista, Botucatu.

SORATTO, R.P.; CRUSCIOL, C.A.C. Atributos químicos do solo decorrentes da aplicação em superfície de calcário e gesso em sistema plantio direto recém-implantado. Revista Brasileira de Ciência do Solo, v.32, p.675-688, 2008a.

SORATTO, R.P.; CRUSCIOL, C.A.C. Dolomite and phosphogypsum surface application effects on annual crops nutrition and yield. Agronomy Journal, v.100, p.261-270, 2008b.

SOUSA, D.M.G.; LOBATO, E.; REIN, T.A. Uso do gesso agrícola nos solos dos Cerrados. Planaltina: EMBRAPACPAC, 1996. 20p. (Circular Técnica, 32)
SUMNER, M.E.; SHAHANDEH, H.; BOUTON, J.; HAMMEL, J. Amelioration of an acid soil prolife through deep liming an surface application of gypsum. Soil Science Society American Journal, v.50, p.1254-1278, 1986.

TOMA, M., SUMNE, M.E.; WEEKS, G.; SAIGUSA, M. Longterm effects of gypsum on crop yield and subsoil chemical properties. Soil Science Society of America Journal, v.63, p.891-895, 1999.

VALE, L.S.R. Doses de calcário, desenvolvimento da planta, componentes de produção, produtividade de grãos e absorção de nutrientes de duas cultivares de feijão (Phaseolus vulgaris L.). 1994. 71f. Dissertação (Mestrado em Agronomia/ Agricultura) - Faculdade de Ciências Agronômicas, Universidade Estadual Paulista, Botucatu.

YOSHIDA, S. Rice. In: ALVIM, P.T.; KOLZWSKI, T.T. Ecophisiology of tropical crops. New York: Academic Press, 1977. p.57-87. 